\title{
Ameliorative Effect of Olive Seed or Nano-olive Seed Powder Against Endothelial Dysfunction Induced by High Fat-High Fructose Diet in Rats
}

\author{
Eman Hosny Fhamy Genedy ${ }^{1}$, Enas Ali Kamel Mohamed ${ }^{1, ~ *, ~ E m a n ~ H a s s a n ~ A b d e l ~ A z i z ~ S h a r a f ~}{ }^{1}$, \\ Nehad Naem Hamed Shosha ${ }^{1}$, Sameh Hamed Ismail ${ }^{2}$ \\ ${ }^{1}$ Department of Biochemistry and Nutrition, Faculty of Women for Arts, Science and Education, Ain Shams University, Cairo, Egypt \\ ${ }^{2}$ Egypt Nanotechnology Center, Cairo University, Giza, Egypt
}

Email address:

Enas.mohamed@women.asu.edu.eg (E. A. K. Mohamed)

${ }^{*}$ Corresponding author

\section{To cite this article:}

Eman Hosny Fhamy Genedy, Enas Ali Kamel Mohamed, Eman Hassan Abdel Aziz Sharaf, Nehad Naem Hamed Shosha, Sameh Hamed Ismail. Ameliorative Effect of Olive Seed or Nano-olive Seed Powder Against Endothelial Dysfunction Induced by High Fat-High Fructose Diet in Rats. International Journal of Food Science and Biotechnology. Vol. 5, No. 4, 2020, pp. 84-96. doi: 10.11648/j.ijfsb.20200504.18

Received: October 29, 2020; Accepted: November 23, 2020; Published: December 8, 2020

\begin{abstract}
Finding new uses for wastes of table olive and olive oil production are of great value to the economy, environment, and human health. This study was designed to investigate the possible modulatory effect of nano or native olive seeds powder (OSP) against endothelial dysfunction induced by high fat high fructose (HFHF) diet in rats. For the current work, 60 adult male Sprague-Dawley rats weighing $120 \mathrm{~g} \pm 5 \mathrm{~g}$ were divided into six groups 10 rats for each group. Group 1: rats were fed a balanced diet and served as normal control. Group 2: rats were fed HFHF diet served as positive control rats diet for 8 weeks. Group 3: rats were fed HFHF diet supplemented with 5\% olive seeds powder. Group 4: rats were fed HFHF diet supplemented with $10 \%$ olive seeds powder. Group 5: rats were fed HFHF diet supplemented with 5\% nano olive seeds. Group 6: rats were fed HFHF diet supplemented with $10 \%$ nano olive seeds. Results of phytochemical analysis of (OSP) showed that each 100g of OSP contains $1004.9 \mathrm{mg}$ total polyphenols as gallic acid equivalent (GAE\%) and $24 \mathrm{mg}$ total flavonoids as quercetin equivalent (QE\%). Results of the biochemical analysis indicated that feeding HFHFdiet caused a significant increment in serum glucose, insulin level, calculated HOMA-IR, lipids profile total cholesterol (TC), triacylglycerols (TAGs), low density lipoprotein cholesterol (LDL-C), very low density lipoprotein cholesterol (VLDL-C), lipase enzyme activity with a significant decrease in high density lipoprotein cholesterol (HDL-C) as compared to control group. Also, interleukin-6 (IL-6) and C-reactive protein (CRP), malondialdehyde (MDA), Endothelin (ET-1), vascular-cellular adhesion molecule-1 (VCAM-1), and E- selectin were significantly increased in HFHF fed rats as compared to the control group. Whereas, serum nitric oxide, prostacyclin, endothelial nitric oxide synthase (eNos) activity were significantly decreased in HFHF fed rats as compared to the control group. These results suggesting that feeding rats HFHF diet for 8 weeks induced endothelial dysfunction. Also, the histopathological examination of aorta sections supported results of biochemical analysis showed significant swelling and corrugation of the endothelial cells that lining the intima in the untreated HFHF group as compared to the control group. Results confirmed that dietary supplementation with olive seed powder either in native or in nano form at the tested doses reversed both alterations biochemical parameters and pathological changes in aorta tissue. Moreover, Nano form showed a more powerful effect than native powder.
\end{abstract}

Keywords: Olive Seed Powder, Endothelial Dysfunction, Nano, Fructose, Rats

\section{Introduction}

Endothelium is an active inner layer of the blood vessel. It generates many factors that regulate vascular tone, adhesion of circulating blood cells, smooth muscle proliferation, and inflammation. Also, the endothelium is responsible for maintaining a relaxed vascular tone and low levels of oxidative stress by releasing mediators such as nitric oxide (NO), prostacyclin (PGI2), and endothelin-1 (ET $)_{1}$ [1]. 
Endothelial dysfunction is characterized by an imbalance between vasodilation and vasoconstriction, elevated reactive oxygen species (ROS), and proinflammatory factors, as well as deficiency of nitric oxide (NO) bioavailability, and is known to precede overt coronary artery disease $[2,3]$.

Fructose is widely used as a sweetener in many processed foods and beverages. The consumption of processed foods and beverages has increased dramatically over the past few decades. There is increasing evidence that high dietary fructose consumption causes dyslipidemia, insulin resistance, obesity, and endothelial dysfunction [4]. All of these factors are associated with an increased risk of cardiovascular diseases (CVD), one of the main causes of morbidity and mortality worldwide $[5,6]$.

Also, the consumption of high fat diet significantly impairs glucose tolerance and oxidative stress with the induction of dyslipidemia [7]. Moreover, long term feeding of a western diet characterizes by foods rich in saturated fat and sugars, contributes to endothelial dysfunction and aortic remodeling in adult rats [8].

Olive seed is considered an interesting source of potent antioxidants such polyphenolic compounds as hydroxytyrosol, gallic acid, oleuropein, and ferulic acid. It also a valuable source for flavonoid components as narengenin, rutin, quercetin [9].

The major challenges of dietary polyphenols include their poor water solubility and oral bioavailability [10]. With the aid of nanoencapsulation, absorption, and circulation of bioactive food components appear to increase in vivo, which assists in achieving the desired concentration and biological activity of these compounds [11]. Therefore, the objective of this study is to investigate the effect of olive seeds powder either in native or in nano form on endothelial dysfunction induced by high fructose high fat diet.

\section{Materials and Methods}

\subsection{Materials}

\subsubsection{Chemicals}

Olive fruit was purchased from the Ministry of Agriculture, Cairo, Egypt. Fructose was purchased from El Gomhoria Co., Cairo, Egypt. Kits for estimation of glucose, lipids profile, MDA, and nitric oxide were purchased from biodiagnostic Co., Cairo, Egypt. Insulin, C-reactive protein, prostacyclin, endothelin-1, VCAM-1, and eNOS ELIZA kits were purchased from My Biosource Co., USA. IL-6 kit was purchased from Quantikine Co., Japan, and Lipase activity kit was purchased from Abnova Co., Japan.

\subsubsection{Animals}

Sixty healthy adult male albino rats "Sprague - Dawely" strain weighing $100-120 \mathrm{~g}$ were used. The animals were obtained from the National Research Center, Dokki, Giza, Egypt. Rats were randomly housed individually in stainless steel cages with a constantly controlled environment; temperature $25^{\circ} \mathrm{C} \pm 5^{\circ} \mathrm{C}$, air humidity $55 \% \pm 10 \%$, and $12 / 12$ hrs light/dark were held. All rats were offered a balanced diet with drinking water ad libitum for a week for adaptation.

\subsubsection{Diet}

The experimental diets used in the present study were the balanced diet that prepared according to AIN- 93 adjusted by Reeves et al. [12] and high fructose -high fat diet (HFHF) which contain $(30 \%)$ fructose and $(45 \%)$ fat that was prepared according to Yoo et al. [13].

\subsection{Methods}

\subsubsection{Preparation of Olive Seeds Powder}

Olive seeds were washed and dried for seven days then grinded by using an electric blender (Panasonic) and the powder formed was sieved until certain sizes were achieved.

\subsubsection{Chemical Analysis of Olive Seed Powder}

The approximate composition of moisture, protein, fat, total polyphenols, flavonoids, and crude fiber of olive seeds powder were determined in Agriculture Research Center according to Association of Official Analytical Chemists AOAC [14]. Carbohydrate content was calculated by subtracting the sum of moisture, fat, protein, crud fiber from one hundred.

\subsubsection{Preparation of Olive Seeds Nanoparticles}

Ball milling technique was used to prepare olive seed nanoparticles. A $2 \mathrm{~g}$ charge of Olive seeds powder was loaded into ball milling vials of ball mills. The used ball mills in the current experiments consist of a stainless-steel vial, which is mounted on a vibrating plate. The Silicon Carbide ball with a diameter of $0.5 \mathrm{~cm}$ collides repeatedly with the plate and the powder inside the vial for 24 hours.

\subsubsection{Characterization of Nano-Olive Seeds}

Characterization is divided into three classes to characterized physicochemical properties of both olive seeds native and nanoparticles namely Identification, Microscopic, and Index class. Microscopic class is used to identify the morphology and texture of both native and nanoparticles Transmission Electron Microscopy (TEM) by using Jeol, JEM-2100 high-resolution, Japan instrument. Identification was carried out by Powder X-ray Diffraction (XRD) to confirm the synthesis of olive seed nanoparticles without any change in composition due to the synthesis process by using Bruker D8 Discover instrument. Index class was carried out to give information about specific surface area and pore size of both olive seeds particles by Brunauer, Emmett and Teller (BET) and Dubinin-Astakhov (DA) method using Quantachrome, NOVA touch LX2, model; NT2LX-2, USA instrument.

\subsection{Induction of Endothelial Dysfunction}

ED was induced by feeding rats HFHF diet for 8 weeks.

\subsection{Experimental Design}

Sixty rats were randomly divided into six groups: 10 rats for each group. 
Group1: Negative control group, rats were fed on a balanced diet.

Group 1: Positive control group, rats fed HFHF diet.

Group3: Rats fed HFHF diet supplemented with 5\% olive seeds powder.

Group4: Rats fed HFHF diet supplemented with 10\% olive seeds powder.

Group5: Rats fed on HFHF diet, supplemented with 5\% nanoparticles of olive seeds.

Group6: Rats fed on HFHF diet supplemented with $10 \%$ nanoparticles of olive seeds.

\subsection{Sampling}

At the end of the experimental period ( 8 weeks), all rats were fasted for 12 hours (from 7 p.m to 7 a.m) then sacrificed by decapitation. Blood samples were collected from the hepatic portal vein in one centrifuge tube for separation of serum by allowing blood samples left for 15 minutes at room temperature, then centrifuged at $4000 \mathrm{rpm}$ for 20 minutes. Part of serum was used immediately for serum glucose determination and the other part was kept at $-20^{\circ} \mathrm{C}$ in plastic vials until used for biochemical analyses. Aorta was separated from the rats then washed in saline and kept in formalin solution $10 \%$ concentration for histological examination by using hematoxylin and eosin stain $(\mathrm{H}$ and $\mathrm{E}$ stain).

\subsection{Biochemical Analyses}

Fasting serum glucose level was estimated according to the enzymatic colorimetric method as described by Trinder, [15]. Serum insulin was estimated using rat insulin ELISA Kit as described by Sapin et al. [16]. Meanwhile, homeostatic model assessment of insulin resistance (HOMA-IR) was calculated by the following equation according to Matthews et al. [17].

$$
(\text { HOMA-IR })=\frac{\text { Fasting glucose conc }\left(\frac{\mathrm{mg}}{\mathrm{dl}}\right) \times \text { Fating insulin } \operatorname{conc}\left(\frac{\mathrm{IU}}{\mathrm{ml}}\right)}{405} .
$$

Serum Lipase activity was determined calorimetrically as described by Lombard et al. [18]. Total Cholesterol, Triacylglycerols, and HDL-C were assayed calorimetrically as described by Allain et al. [19], Fassati, and Prencipe [20], and Lopez-Virella et al. [21], respectively. Finally, LDL-C and VLDLL-C were calculated according to Friedewald et al. [22]. By the following equation:

$$
\begin{gathered}
\text { LDL- cholesterol }(\mathrm{mg} / \mathrm{dl})=\mathrm{TC}-(\mathrm{VLDL}-\mathrm{C}+\mathrm{HDL}-\mathrm{C}) \\
\text { VLDL-cholesterol }(\mathrm{mg} / \mathrm{dl})=\mathrm{TAGs} / 5
\end{gathered}
$$

Serum C- reactive protein (CRP), interleukin -6 (Il-6), prostacyclin, Endothelin-1, vascular adhesion molecules (VCAM-1), and E-selectin were measured by the quantitative sandwich enzyme immunoassay technique according to Roberts et al. [23] Peters et al. [24] Docherty and Gerrard [25]- Wakisaka et al. [26] Besemer et al. [27] Zheng et al. [28], respectively. Serum Malondialdehyde (MDA) and
Nitric oxide were measured colorimetrically as described by Ohkawa et al. [29], Montgomery, and Dymock [30]. eNOS activity as described by Banchroft et al. [31].

\subsection{Histopathological Examination}

Aorta tissue specimen was collected and preserved in 10\% formalin solution for microscopic examination. Part of aorta specimens embedded in paraffin wax and tissue blocks were sectioned into $5 \mu \mathrm{m}$ thick slices. The obtained tissue sections were stained with hematoxylin and eosin H\&E stain [32]. The slides were examined under light microscope at a magnification power X 400 .

\subsection{Statistical Analysis}

Data were statistically analyzed by Statistical Package for Social Science (SPSS) version 16.0 statistical packages. Values were presented as mean \pm standard deviation (S. D). Statistical differences between groups were performed using one way ANOVA, the mean difference was significant at the level $(\mathrm{p}<0.05)$ level according to [33].

\section{Results and Discussion}

\subsection{Chemical Analysis of Olive Seed Powder}

Table 1 showed the approximate chemical composition of native olive seeds in $100 \mathrm{~g}$ dried sample. Results showed that the protein content was $28 \%$, indicating high level protein in olive seeds in comparison with the olive fruit as previously described by the results of [34].

Also, the results of Bianchi [35] supported the results of the current study by confirming that olive seed contains a considerable amount of fat as oil (22-27\%.). Furthermore, The current results showed that the fiber content of olive seeds was $23.81 \%$.In the olive seed, fiber is the major active component of olive seed mainly as cellulose and hemicellulose as previously reported by Rodriguez et al. [34] and Naghmouchi et al. [36].

Table 1. The nutritive value of olive seeds in $100 \mathrm{~g}$ dried sample.

\begin{tabular}{ll}
\hline Olive seeds chemical composition & $\mathbf{g} / \mathbf{1 0 0 g}$ \\
\hline Protein & 28.68 \\
Fat & 17.42 \\
Carbohydrate & 14.52 \\
Crude fiber & 23.81 \\
Moisture & 0.5 \\
Total polyphenols & 1.0049 \\
Flavonoids & 0.024 \\
\hline
\end{tabular}

\subsection{Characterization of Native and Nano Olive Seeds}

Zeta sizing was carried out for both olive seeds nanoparticles and olive seeds as shown in Figure 1 Zeta sizing curve illustrated the different sizes for olive seeds nanoparticles but all of them in nano size. However, this high particle size distribution due to ball mill methods which give various sizes. Zeta sizing of olive seeds is $1.4 \mu \mathrm{m}$.

Transmission Electronic Microscope (TEM) images 
showed in Figure 2 carried out at magnification allow identifying the individual nanoscale size particles, agglomeration, and concentration. The shape of the individual olive seed nanoparticles is subspherical to sub cubic with a size range from 35 to $65 \mathrm{~nm}$. The homogenous particles are good with large particle size distribution. TEM image of olive seeds illustrated the cubic to subcubic shape with a size of about $1 \mu \mathrm{m}$.

X-ray diffraction (XRD) pattern show similarity of olive seeds and olive seeds nanoparticles which indicated the successfulness of the synthesis method to convert micron size olive seeds to nano one without any destruction or decomposition for the origin structure of olive seeds by ball milling. The characteristic very sharp peaks for olive seed and olive seeds nanoparticles at $2 \theta=15,21.6,30.4,31.9,35$, $38.65,43.76,45.8$ and $75.7^{\circ}$ where Broad weak peaks at $2 \theta=16.77$ and $41.93^{\circ}$ as shown in Figure 3. The well- formation olive seeds nanoparticles with high purity confirm that the ball mill method is an effective and simple method for the synthesis of olive seed nanoparticles.

The BET surface area, DA pore size, and volume results are presented in Figure 4 Olive seed and olive seed nanoparticles have multipoint BET around $20.7 \mathrm{~m}^{2} \cdot \mathrm{g}^{-1}$ and $96.8 \mathrm{~m}^{2} \cdot \mathrm{g}^{-1}$ for olive seed and olive seeds nanoparticles, respectively. Olive seed and olive seed nanoparticles have almost the same average pore size of $1.67 \mathrm{~nm}$ and a total pore volume of $0.0174 \mathrm{cc} / \mathrm{g}$. DA pore size and volume showed good diffusion rates of gas molecules into pores and high surface area per unit volume. The nitrogen adsorptiondesorption isotherm curve shows type IV isotherms which illustrated the presence of microporous structures. The high BET surface area of olive seed nanoparticles makes it very high chemical activity which increased its bioactivity.
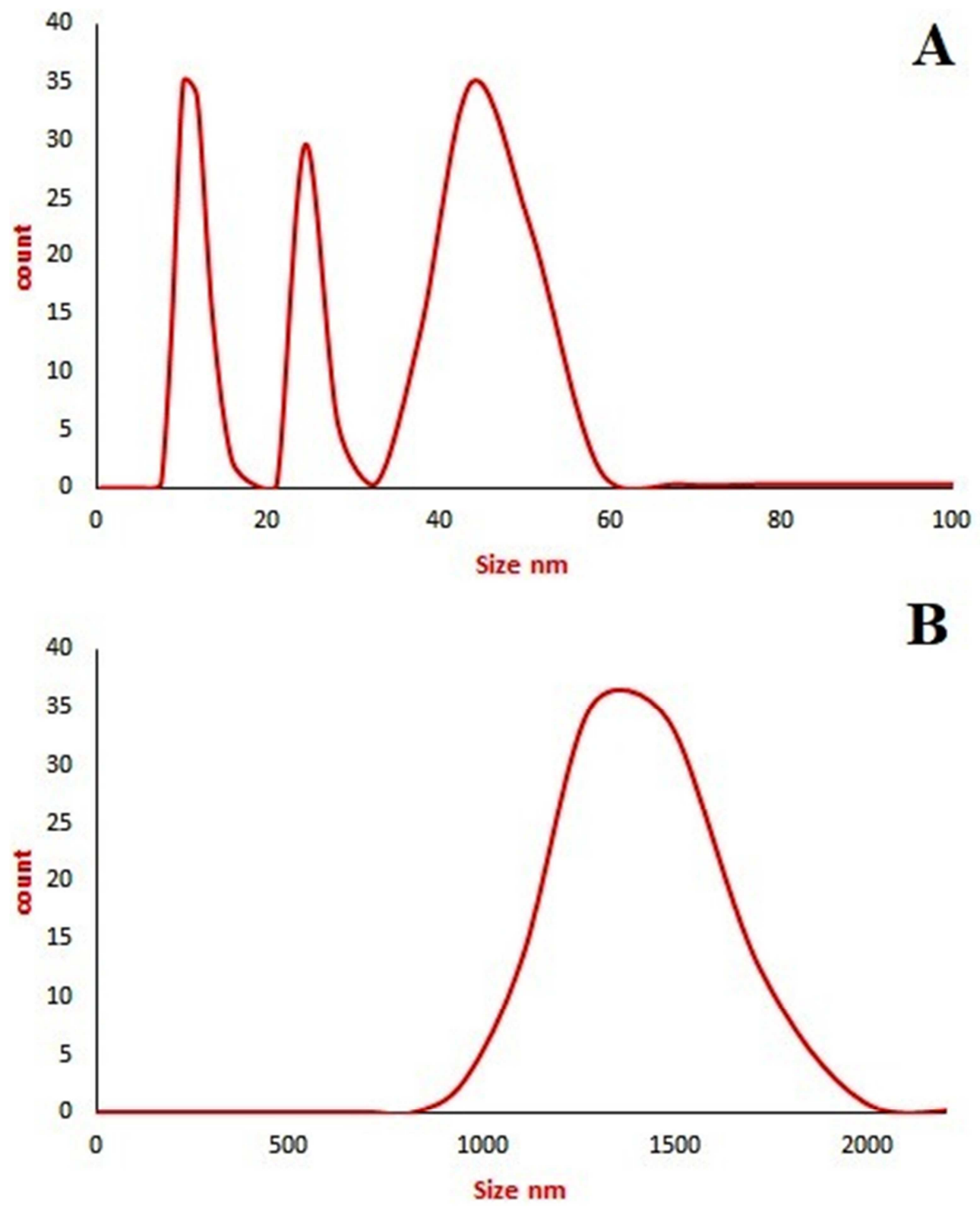

Figure 1. Zeta sizing curve of a) olive seeds powder and b) olive seed nanoparticles. 


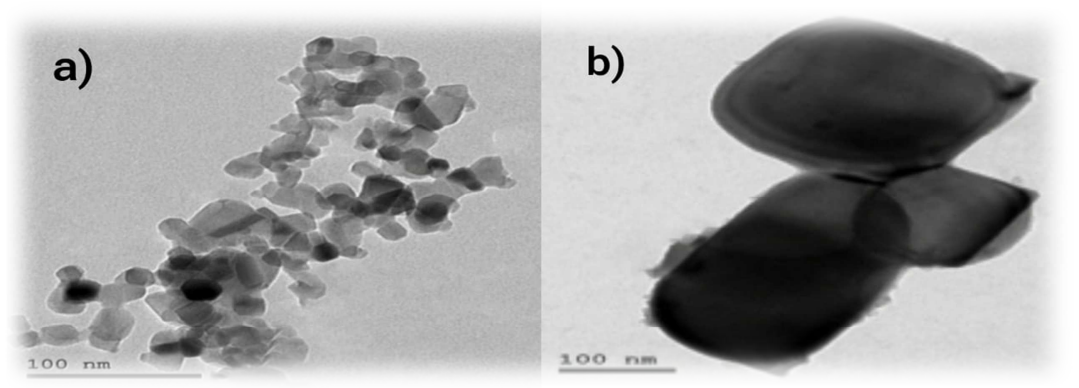

Figure 2. TEM image of olive seeds nanoparticles (a) and native olive seeds (b).

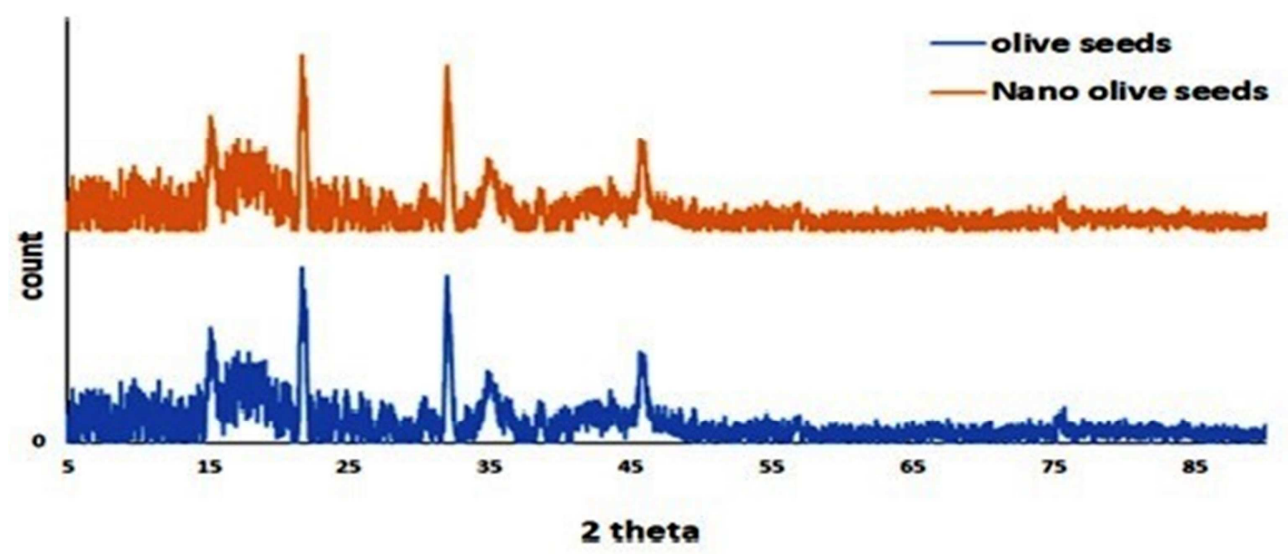

Figure 3. XRD pattern of both types of native olive seed and olive seeds nanoparticles.

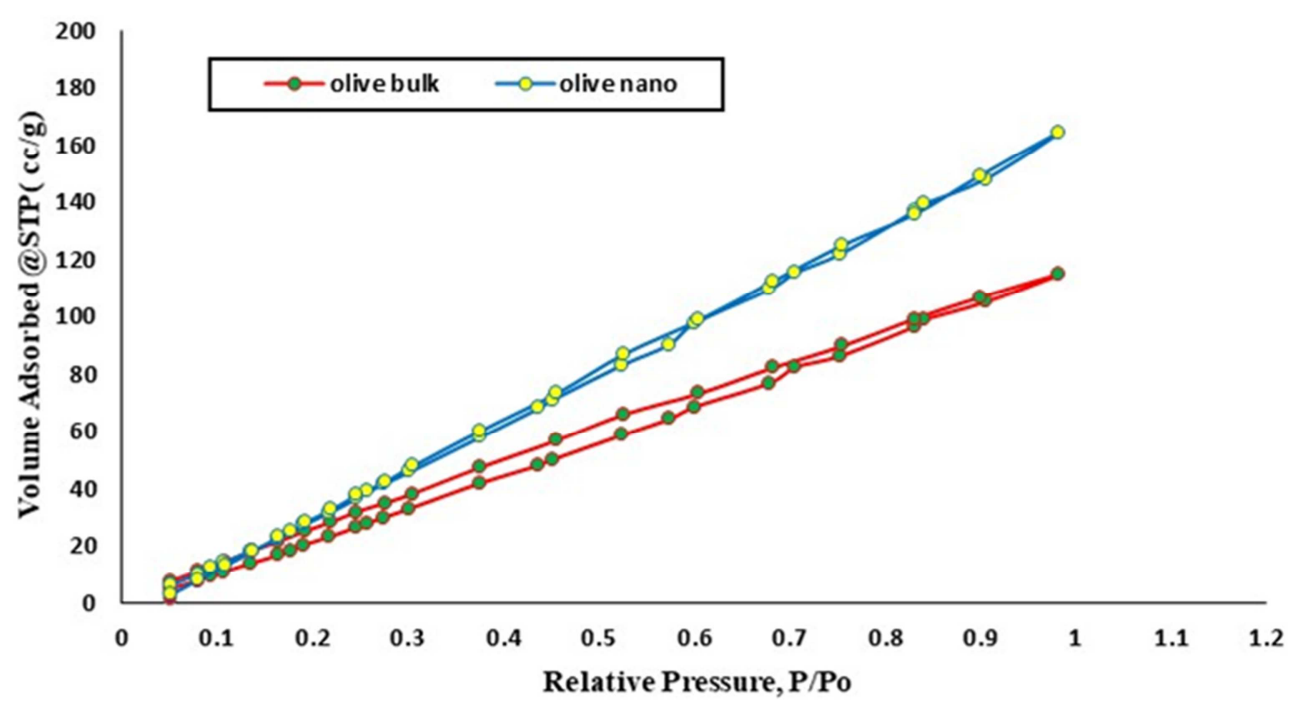

Figure 4. DA pore Size of native olive seed (a) and olive seeds nanoparticles (b).

\subsection{Effect of Native or Nano Olive Seeds on Serum Glucose, Insulin Levels and Calculated HOMA-IR in Experimental Groups}

Data from Table 2 revealed that there was a statistically significant increase in serum glucose and insulin levels with a consequence elevation of calculated HOMA-IR indicating insulin resistance in rats fed on HFHF diet for 8 weeks when compared to the healthy control group $(\mathrm{p}<0.05)$. Otherwise, supplementation with olive seeds powder either in a native or nano form had a significant effect in modulating these altered parameters and reversed them near to their normal levels. The more significant reduction in serum glucose and insulin levels were observed in both HFHF group supplemented with $5 \%$ and $10 \%$ native olive seeds when compared to HFHF group. Besides, the results of the present work showed that the supplementation with olive seeds either in native or nano form showed nearly a similar effect on HOMA-IR. 
Table 2. The effect of native or nano olive seeds on (Blood glucose, serum insulin levels, and HOMA-IR) in all experimental rat groups.

\begin{tabular}{|c|c|c|c|c|c|c|}
\hline Parameters & $\begin{array}{l}\text { Healthy control } \\
\text { group }\end{array}$ & HFHF group & $\begin{array}{l}\text { HFHF }+5 \% \text { olive } \\
\text { seed group }\end{array}$ & $\begin{array}{l}\text { HFHF + 10\% } \\
\text { olive seed group }\end{array}$ & $\begin{array}{l}\text { HFHF + 5\% nano } \\
\text { olive seed group }\end{array}$ & $\begin{array}{l}\text { HFHF }+10 \% \text { nano } \\
\text { olive seed group }\end{array}$ \\
\hline Blood glucose $(\mathrm{mg} / \mathrm{dl})$ & $92.78 \pm 7.86^{\mathrm{a}}$ & $156.46 \pm 1.80^{b}$ & $101.12 \pm 4.46^{\mathrm{c}}$ & $99.77 \pm 6.42^{\mathrm{c}}$ & $94.43 \pm 0.30^{\mathrm{a}, \mathrm{c}}$ & $97.31 \pm 6.83^{\mathrm{a}, \mathrm{c}}$ \\
\hline Insulin $(\mu \mathrm{IU} / \mathrm{ml})$ & $1.16 \pm 0.13^{\mathrm{a}}$ & $3.13 \pm 0.22^{\mathrm{b}}$ & $2.14 \pm 0.30^{\mathrm{c}}$ & $2.09 \pm 0.13^{\mathrm{c}}$ & $2.42 \pm 0.21^{\mathrm{d}}$ & $2.41 \pm 0.26^{\mathrm{d}}$ \\
\hline
\end{tabular}

Values are represented as mean $\pm \mathrm{SD}(\mathrm{n}=8)$.

There was no significant difference between means have the same letter in the same column $(\mathrm{P}<0.05)$

Several hypotheses have been proposed to explain the development of insulin resistance in fructose fed conditions, including impairment of intracellular insulin signaling pathway, a change in the activities of several enzymes regulating hepatic glucose metabolism, and a generation of reactive oxygen species (ROS) Basciano et al. [37], Tran et al. [38].

Insulin resistance is frequently associated with other abnormalities that impair endothelial function, such as hyperglycemia, hypertension, dyslipidemia, and altered coagulation/fibrinolysis. Also, it contributes to obesity [39, 40]

The results of Lozano et al. [41] supported the result of the current study, which reported that consumption of high fat high -fructose diet induced fasting hyperglycemia and hyperinsulinemia complicated with vascular complications and endothelial dysfunction.

Several previous works confirmed the beneficial effect of some structural components of olive seeds in modulating insulin resistance. Oleuropin (an active component in olive seeds) is reported to act as a-glucosidase inhibitors, reducing the absorption of carbohydrates in the gut so act as a hypoglycemic agent [42].

Also, (HT) as an active component in olive seeds significantly decreased fasting hyperglycemia and increases insulin sensitivity leading to a decrease in homeostatic model assessment-insulin resistance [43] and enhances glucose tolerance and increases insulin sensitivity, leading to a decrease in homeostatic model assessment-insulin resistance [44].

Naringenin is an important constituent of olive seed powder [9] that can absorb glucose from the intestine of diabetic rats [45]. In mice fed high fat diet, Naringenin could improve insulin resistance via activation of the AMPactivated protein kinase pathway [46]. The main problem of Naringenin could be attributed to the fact that it is poorly dissolved in water and poorly absorbed in the intestine after oral administration due to the quick elimination by diverse enzymes located in the gut and liver [47]. Therefore, nanosizing this flavanone and/or loading it onto NPs, or encapsulating it in a nanoformulation can be considered as practical methods to improve its bioavailability [48].

Oleanolic acid is an active component of olive seed [9] that improves hepatic insulin resistance through antioxidant, hypolipidemic and anti-inflammatory activities in $\mathrm{db} / \mathrm{db}$ diabetic mice. Furthermore, the ability of nano-oleanolic acid to mitigate insulin resistance is more potent than oleanolic acid in the native form [49].

The significant reduction in glucose and insulin levels caused by olive seed supplementation may be also related to the high insoluble fiber content as cellulose. Cellulose can reduce insulin resistance and the risk of developing type 2 diabetes (T2D) by about 20-30\% [50]. Hence, it appears that fiber intake increases insulin sensitivity by changing both adipose tissue and skeletal muscle metabolism.

\subsection{Effect of Native or Nano Olive Seeds on Lipids Profile (TC, TAGs, HDL-C, LDL-C and VLDL-C levels) and Lipase Enzyme in Experimental Groups}

The current results summarized in Table 3 showed that feeding HFHF diet for 8 weeks resulted in a significant increase in serum TC, TAGs, LDL-C, VLDL-C, and lipase enzyme activity with a significant reduction in HDL-C as compared to the healthy control group $(\mathrm{p}<0.05)$. Results also demonstrated that dietary supplementation with olive seeds either in native or in nano form showed a significant improvement in these altered parameters $(\mathrm{p}<0.05)$. There was a marked improvement in lipids profile in the rat group supplemented with $10 \%$ nano olive seeds, which was nearly approached that of the healthy control group with no significant difference observed in comparison with healthy control $(\mathrm{p}<0.05)$.

Table 3. The effect of native or nano olive seeds on serum lipids profile (TC, TAGs, HDL-C, \& LDL-C) levels and lipase enzyme activity in all experimental rat groups.

\begin{tabular}{lllllll}
\hline Parameter & $\begin{array}{l}\text { Healthy } \\
\text { control group }\end{array}$ & HFHF group & $\begin{array}{l}\text { HFHF + 5\% } \\
\text { olive seed group }\end{array}$ & $\begin{array}{l}\text { HFHF + 10\% } \\
\text { olive seed group }\end{array}$ & $\begin{array}{l}\text { HFHF + 5\% nano } \\
\text { olive seed group }\end{array}$ & $\begin{array}{l}\text { HFHF + 10\% nano } \\
\text { olive seed group }\end{array}$ \\
\hline Total cholesterol (TC) (mg/dl) & $60.82 \pm 4.39^{\mathrm{a}}$ & $83.86 \pm 3.05^{\mathrm{b}}$ & $71.32 \pm 2.74^{\mathrm{c}}$ & $69.50 \pm 5.43^{\mathrm{c}}$ & $73.12 \pm 1.13^{\mathrm{c}}$ & $62.54 \pm 8.60^{\mathrm{a}}$ \\
Triacylglycerol (TAGs) (mg/dl) & $47.51 \pm 6.90^{\mathrm{a}}$ & $109.75 \pm 3.70^{\mathrm{b}}$ & $91.16 \pm 13.06^{\mathrm{c}}$ & $63.25 \pm 5.96^{\mathrm{d}}$ & $62.08 \pm 5.14^{\mathrm{d}}$ & $48.49 \pm 3.74^{\mathrm{a}}$ \\
High density lipoprotein (HDL-C) (mg/dl) & $44.19 \pm 2.08^{\mathrm{a}}$ & $35.12 \pm 3.11^{\mathrm{b}}$ & $43.61 \pm 3.19^{\mathrm{a}}$ & $43.69 \pm 2.14^{\mathrm{a}}$ & $41.50 \pm 6.79^{\mathrm{a}}$ & $43.31 \pm 3.92^{\mathrm{a}}$ \\
Low density lipoprotein (LDL-C) (mg/dl) & $7.23 \pm 0.20^{\mathrm{a}}$ & $26.83 \pm 0.077^{\mathrm{b}}$ & $9.34 \pm 0.017^{\mathrm{c}}$ & $12.89 \pm 0.039^{\mathrm{d}}$ & $9.35 \pm 0.069^{\mathrm{c}}$ & $9.61 \pm 0.015^{\mathrm{c}}$ \\
Lipase enzyme activity (U/L) & $107.10 \pm 4.50^{\mathrm{a}}$ & $399.83 \pm 18.20^{\mathrm{b}}$ & $196.98 \pm 6.76^{\mathrm{c}}$ & $189.02 \pm 10.27^{\mathrm{c}}$ & $197.96 \pm 9.96^{\mathrm{c}}$ & $176.87 \pm 8.22^{\mathrm{d}}$ \\
\hline
\end{tabular}

Values are represented as mean $\pm \mathrm{SD}(\mathrm{n}=8)$.

There was no significant difference between means have the same letter in the same column $(\mathrm{P}<0.05)$.

In the present study, HFHF diet leads to dyslipidemia manifested by a significant increase in TC, TAGs, and LDL-
$\mathrm{C}$ with a significant decrease in HDL-C levels as compared to the normal control group $(\mathrm{p}<0.05)$. A high-fat and high- 
calorie diet can cause dyslipidemia and thereafter endothelial dysfunction [51]. Previous work of Zhuhua et al. [52] reported that rats fed a high-fructose diet $(60 \%)$ or high-fat and high-fructose developed dyslipidemia, especially hypertriglyceridemia, insulin resistance, and hypertension which consider the main risk factors associated with CVD. HFHF diet induced a significant reduction in serum HDL-C level and elevation of serum TAGs, TC, LDL-C, glucose, and insulin levels in mice [53]. The elevation in triacylglycerol is explained by Angelopoulos et al. [54] reported that fructose is metabolized in the liver into glyceraldehyde and dihydroxyacetone phosphate, ultimately becoming triacylglycerols (de novo lipogenthesis).

The results of the present study confirmed that nano olive seeds improved lipids profile and lipase enzyme activity more than its native form. The results were confirmed by [9] work, demonstrated that all rats fed a hypercholesterolemic diet supplemented with olive seeds powder $(5 \%$ \& $10 \%)$ showed a significant decrease in serum LDL-C and TAGs as compared to the positive control rats. Furthermore, [55] demonstrated that olive seed hydrolysate showed hypolipidemic activity by reducing serum cholesterol in mice at two different concentration levels (200 and 400 $\mathrm{mg} / \mathrm{kg} /$ day). This effect was attributed to a reduction in the micellar cholesterol solubility and inhibition of important enzymes (pancreatic lipase and cholesterol esterase) involved in the biosynthesis and absorption of cholesterol.

Many different constitutes were identified in the olive seed that could be responsible for the observed hypolipidemic effect. One of these components is dietary fiber, especially insoluble fiber. The effect of dietary fiber is related to different mechanisms including a reduction in the absorption of TAGs, an increase in the synthesis and excretion of bile acids, and an inhibition of the endogenous synthesis of cholesterol by short-chain fatty acids [56].

The results of Yu et al. [57] reported that cellulose particle size in a nano form had a strong adsorption capacity towards fats, cholesterol. There were positive correlations between decreasing plasma TC, TAGs and LDL-C, and cellulose particle size. Also, Abdelbaky et al. [58] demonstrated that rats fed on a hypercholesterolemic diet supplemented with nano-cellulose from grape seeds $(2 \% \& 4 \%)$ showed a significant decrease in serum TC, TAGS, LDL-C, and VLDL-C as compared to rats fed high fat high cholesterol diet.

Another study of Paiva-Martins and Kiritsakis [59] investigated the anti-oxidant effect of olives active components as oleuropein and HT via maintenance of HDL$\mathrm{C}$ function. Results showed that dietary supplementation with olives active components for a long period can induce HDL$\mathrm{C}$ resistance against oxidation, and therefore, its vasodilator capacity. Also, HDL-C was able to induce the release of nitric oxide in endothelial cells by activating (eNOS).

Ferulic acid as a component of olive seed powder [9] showed a potential inhibitory effect on LDL-C oxidation in vitro [60]. In the same line with the results of this study, Assini et al [61] reported that Naringrnin (one of the active components of olive seeds) is found to prevent the production of free fatty acids, hepatic steatosis, and VLDL-C in mice. Also, Bunbupha et al. [62] demonstrated that gallic acid reversed dyslipidemia in rats fed with a high fructose diet (HFD) by decreasing plasma cholesterol and triacylglycerols level.

\subsection{The Effect of Native or Nano Olive Seeds on Serum Inflammatory Markers (II-6 and CRP) and Oxidative Stress Marker (MDA) in Experimental Groups}

It is clear from the results illustrated in Table 4 that there was a statistically significant increase in serum IL-6, CRP, and MDA levels in HFHF group as compared to the healthy control group $(\mathrm{P}<0.05)$. Both native and nano olive seed supplementation cause a significant improvement in inflammatory markers and lipid peroxidation. This may be due to the effective antiinflammatory and anti-oxidative activity of the active components in olive. The ameliorative effect against inflammation and oxidative stress was more pronounced in 10\% nano olive seed supplemented group as compared with those treated with 5\% nano-olive seed or with native seed olive seeds.

Table 4. The effect of native or nano olive seeds on serum inflammatory markers (IL-6 and CRP) and oxidative stress marker (MDA) in experimental groups.

\begin{tabular}{|c|c|c|c|c|c|c|}
\hline Parameters & $\begin{array}{l}\text { Healthy } \\
\text { control }\end{array}$ & $\begin{array}{l}\text { HFHF } \\
\text { group }\end{array}$ & $\begin{array}{l}\text { HFHF }+5 \% \text { olive } \\
\text { seed group }\end{array}$ & $\begin{array}{l}\text { HFHF }+10 \% \\
\text { olive seed group }\end{array}$ & $\begin{array}{l}\text { HFHF + } 5 \% \text { nano } \\
\text { olive seed group }\end{array}$ & $\begin{array}{l}\text { HFHF + } 10 \% \text { nano } \\
\text { olive seed group }\end{array}$ \\
\hline Interlukin -6 (IL-6) (pg/ml) & $22.15 \pm 3.97^{\mathrm{a}}$ & $108.72 \pm 8.67^{b}$ & $56.28 \pm 1.68^{c}$ & $45.17 \pm 2.84^{\mathrm{d}}$ & $59.47 \pm 5.85^{\mathrm{c}}$ & $41.33 \pm 5.92^{\mathrm{d}}$ \\
\hline C- reactive protein $(\mathrm{CRP})(\mathrm{ng} / \mathrm{ml})$ & $83.54 \pm 1.18^{\mathrm{a}}$ & $216.02 \pm 5.51^{b}$ & $127.91 \pm 4.96^{\mathrm{c}}$ & $115.21 \pm 4.06^{\mathrm{d}}$ & $114.56 \pm 2.70^{\mathrm{d}}$ & $111.80 \pm 0.69^{d}$ \\
\hline Malondialdyhyde (MDA) (nmol/L) & $11.55 \pm 1.07^{\mathrm{a}}$ & $90.11 \pm 6.34^{\mathrm{b}}$ & $46.32 \pm 2.54^{\mathrm{c}}$ & $32.82 \pm 2.23^{\mathrm{d}}$ & $25.47 \pm 2.52^{\mathrm{e}}$ & $18.95 \pm 0.69^{\mathrm{f}}$ \\
\hline
\end{tabular}

Values are represented as mean $\pm \mathrm{SD}(\mathrm{n}=8)$.

There was no significant difference between means have the same letter in the same column $(\mathrm{P}<0.05)$

High fructose feeding was also associated with an increase in reactive oxygen species (ROS) production [63] which can be a key event in the initiation of ED [64] and development of cardiovascular complications associated with insulin resistance [65]. There is evidence that fructose and its metabolites cause advanced glycation end products (AGEs) formation and subsequently ROS production, leading to lipid peroxidation [66].
Polyphenols in olives and its derivatives as luteolin, HT, and oleuropein inhibited superoxide anion-mediated impairment of endothelium, improved endothelium, dependent relaxation in rat's aorta tissue by modulating the action of high fat diet and inflammatory markers [67]. HT supplementation reduced the inflammatory status and also, inhibited platelet aggregation and scavenging of free radicals [68]. Another study of Bulotta et al. [69] confirmed that phenolic compounds as oleuropein 
and HT showed a potent antioxidant activity by scavenging intracellular ROS and free nitric oxide, reducing the formation of other powerful oxidants such as peroxynitrite.

The present work was agreed with the study of Liu et al. [70] reported that polyphenolic compounds have the ability to ameliorate endothelial dysfunction by inhibiting inflammatory mediators as IL-6 production and prevention of insulin resistance.

Naringenin was found to be effective in scavenging ROS and preventing DNA damage [71]. It was also found to increase the level of antioxidant enzymes [72]. Moreover, Naringenin was found to ameliorate proinflammatory reaction mediated by TNF- $\alpha$, IL-6, and also prevent metabolic dysregulation [73, 74]. The high fiber content in olive seeds is also related to the reduction in systemic inflammation. Some previous studies showed that a diet high in total dietary fiber supplement significantly decreased levels of CRP inflammatory marker CRP [75].

\subsection{The Effect of Native or Nano Olive Seeds on Vasodilator Factors (Prostacyclin, NO and eNOS) and Vasoconstrictor Factor (ET-1) in Experimental Groups}

Results in Table 5 revealed that feeding HFHF diet for 8 weeks resulted in a significant decrease in Prostacyclin, NO, and endothelial nitric oxide synthase (eNOS) activity as compared to the healthy control group $(\mathrm{p}<0.05)$. This decrease in vasodilator factors was accompanied by a significant increase in vasoconstrictor marker endothelin -1 (ET-1), indicating the initiation of endothelial dysfunction $(p<0.05)$. Results also demonstrated that a diet supplemented with olive seeds either in native or in nano form caused a significant improvement in these altered parameters. Supplementation with $10 \%$ nano olive seeds caused the highest significant increase in serum prostacyclin, NO levels, and endothelial nitric oxide synthase activity.

Table 5. The effect of native or nano olive seeds on vasodilator and vasoconstrictor markers in experimental groups.

\begin{tabular}{|c|c|c|c|c|c|c|}
\hline Parameter & $\begin{array}{l}\text { Healthy } \\
\text { control }\end{array}$ & $\begin{array}{l}\text { HFHF } \\
\text { group }\end{array}$ & $\begin{array}{l}\text { HFHF }+5 \% \text { olive } \\
\text { seed group }\end{array}$ & $\begin{array}{l}\text { HFHF + 10\% } \\
\text { olive seed group }\end{array}$ & $\begin{array}{l}\text { HFHF + 5\% nano } \\
\text { olive seed group }\end{array}$ & $\begin{array}{l}\text { HFHF + 10\% nano } \\
\text { olive seed group }\end{array}$ \\
\hline Prostacyclin $(\mathrm{mmol} / \mathrm{L})$ & $203.90 \pm 3.90^{\mathrm{a}}$ & $69.79 \pm 7.04^{\mathrm{b}}$ & $105.34 \pm 2.93^{\mathrm{c}}$ & $109.63 \pm 0.69^{\mathrm{d}}$ & $106.28 \pm 3.99^{\mathrm{c}, \mathrm{d}}$ & $113.56 \pm 1.56^{\mathrm{d}}$ \\
\hline Nitric oxide (NO) $(\mu \mathrm{mol} / \mathrm{L})$ & $46.62 \pm 0.44^{\mathrm{a}}$ & $15.59 \pm 2.62^{b}$ & $18.11 \pm 0.97^{\mathrm{c}}$ & $25.24 \pm 2.09^{d}$ & $28.75 \pm 1.13^{\mathrm{e}}$ & $33.99 \pm 0.63^{\mathrm{f}}$ \\
\hline $\begin{array}{l}\text { Endothelial nitric oxide synthase } \\
\text { (eNOS) (ng/ml) }\end{array}$ & $85.70 \pm 2.90^{\mathrm{a}}$ & $21.80 \pm 2.49^{b}$ & $63.68 \pm 0.818^{\mathrm{c}}$ & $42.17 \pm 0.78^{d}$ & $45.57 \pm 1.4473^{\mathrm{e}}$ & $74.26 \pm 1.28^{f}$ \\
\hline Endothelin- 1 (ET-1) (ng/ml) & $32.74 \pm 2.59^{\mathrm{a}}$ & $95.70 \pm 10.40^{\mathrm{b}}$ & $44.74 \pm 2.81^{\mathrm{c}}$ & $46.11 \pm 1.89^{c}$ & $34.21 \pm 2.25^{\mathrm{a}}$ & $40.36 \pm 3.48^{\mathrm{c}, \mathrm{d}}$ \\
\hline
\end{tabular}

Values are represented as mean $\pm \mathrm{SD}(\mathrm{n}=8)$.

There was no significant difference between means have the same letter in the same column $(\mathrm{P}<0.05)$.

The previous work of Bourgoin et al. [76] is confirmed by the results of the present study, which reported that rats fed a high fat, high sucrose diet for 4 weeks showed a reduction in endothelium dependent blood flow. This is indicated by a decrease in eNOS protein expression, NO production, and increased vascular ET-1 protein content, All these factors contribute to an imbalance in the vascular tone which finally led to ED.

In the same trend, Yoo et al. [13] demonstrated that HFHF induced ED resulted from the disturbance in the production of NO due to the decrease in the generation of eNOS concomitant with the increased secretion of ET1.

Hyperglycemia, hyperlipidemia, and inflammation induce superoxide production. Superoxide reacts with NO forming peroxynitrite (ONOO-), which may cause uncoupling of (eNOS). Uncoupled eNOS produces superoxide instead of NO thus decreasing the bioavailability of NO with a subsequent reduction of the nitric oxide (NO) generation and finally potentiates the preexisting oxidative stress [77]. Peroxynitrite at a high concentration not only reduces NO bioavailability but also inhibits prostacyclin production through the nitration of the prostacyclin synthase [78]. Elevation of ET-1 level may be explained by the oxidative and inflammatory mediators associated such as CRP and TNF- $\alpha$ which upregulate the synthesis of ET-1 from endothelial cells [79]. Therefore, hyperglycemia and hyperlipidemia, induced by HFHF diet, contribute to endothelial dysfunction.
The results of the previous studies of Karbach et al. [77], Luczak et al. [78] and Yeager et al. [79], respectively explained the significant decrease in eNOS activity, serum nitric oxide level, prostacyclin level, with the elevation in serum MDA and ET-1 in rats fed high fat high fructose diet

Supplementation with native or nano olive seeds in HFHF fed rats help in reversing the vasodilator and vasoconstrictor to their normal level, this effect showed the role of olive seeds component in the regulation of vascular tone and in balancing the oxidative stress. One of the possible mechanisms is making a balance in vascular tone is by increasing eNOS expression and NO synthesis and reducing endothelin-1 levels so making a balance in vascular tone [70].

Also, the previous studies of Omar [80] and Summerhill et al. [81], revealed that oleuropein as olive phenolic compounds increased the production of nitric oxide by increasing eNOS activity. Therefore, it may contribute to restoring endothelial function.

\subsection{Effect of Native or Nano Olive Seeds on Vascular Adhesion Molecules (VCAM-1 and E-selectin) in Experimental Groups}

The results of Table 6 showed that there was a statistically significant increment in serum VCAM-1 and E-selectin levels in rats fed on HFHF diet when compared to the healthy control group $(\mathrm{p}<0.05)$. The increase in adhesion molecules with a concomitant increase in vasoconstrictor markers indicating the progression of ED disease. On the other hand, supplementation 
of HFHF diet with either native or nano olive seed powder caused a significant reduction in the elevated levels of VCAM1 and $\mathrm{E}$-selectin compared to HFHF group. The anti-adhesive effect of olive seed was highly marked in $10 \%$ nano olive seeds supplemented group. Also, E -selectin level nearly approaches that level of healthy control which confirm the ameliorative effect of olive seeds nanoparticles against vascular adhesion induced by HFHF diet.

Table 6. The effect of native or nano olive seeds on Adhesion molecules (VCAM and E- selectin) in experimental groups

\begin{tabular}{llllll}
\hline Parameter & $\begin{array}{l}\text { Healthy } \\
\text { control }\end{array}$ & $\begin{array}{l}\text { HFHF } \\
\text { group }\end{array}$ & $\begin{array}{l}\text { HFHF + 5\% } \\
\text { olive seed group olive seed group }\end{array}$ & $\begin{array}{l}\text { HFHF + 10\% } \\
\text { olive seed group }\end{array}$ & $\begin{array}{l}\text { HFHF + 5\% nano } \\
\text { olive seed group }\end{array}$ \\
\hline $\begin{array}{l}\text { Vascular cellular adhesion molecule } \\
\text { VCAM-1 (ng/ml) }\end{array}$ & $44.70 \pm 2.42^{\mathrm{a}}$ & $143.91 \pm 1.35^{\mathrm{b}}$ & $75.25 \pm 2.05^{\mathrm{c}}$ & $77.64 \pm 2.30^{\mathrm{d}}$ & $70.07 \pm 3.47^{\mathrm{e}}$ \\
\begin{tabular}{l} 
E- selectin $(\mathrm{ng} / \mathrm{ml})$ \\
\hline
\end{tabular} & $2.36 \pm 0.35^{\mathrm{a}}$ & $10.18 \pm 0.49^{\mathrm{b}}$ & $4.38 \pm 0.22^{\mathrm{c}}$ & $4.33 \pm 0.37^{\mathrm{c}}$ & $4.60 \pm 0.20^{\mathrm{c}}$ \\
\hline
\end{tabular}

Values are represented as mean $\pm \mathrm{SD}(\mathrm{n}=8)$.

There was no significant difference between means have the same letter in the same column $(\mathrm{P}<0.05)$.

Vascular cell adhesion molecule (VCAM-1), intercellular cell adhesion molecule (ICAM-1) and E-selectin, participate in leukocyte adhesion to the endothelium [82]. VCAM-1 expression is activated by pro-inflammatory cytokines, including TNF- $\alpha$, and also by ROS, oxidized low density lipoprotein, high glucose concentration [83].

Another explanation revealed by Kowalczyk et al. [84] reported that ET-1 enhances the expression of adhesion molecules on vascular endothelial cells and stimulates the aggregation of polymorphonuclear neutrophils (PMNs) contributing to inflammation and endothelial dysfunction.

The results of Leibowitz et al. [85] are similar to the results of the current study indicated that rats fed on high fructose diet for 5 weeks showed a significant increase in expression of (VCAM-1). In addition to the results of Kho et al. [86] indicated that feeding rats high fructose diet for 8 weeks induced a high expression of ET-1, adhesion molecules such as ICAM-1, VCAM-1, and E-selectin in the arterial wall.

Previous results of Crespo et al. [87] supported the results of the current study, demonstrated that HT (as an active component in olive seeds) and its metabolites have a protective effect against ED in human aortic endothelial cells by considerably reducing the secretion of E-selectin and VCAM-1.

\subsection{The Effect of Native or Nano Olive Seeds on Microscopic Examination of Aorta Tissues in All Experimental Rat Groups}

The histopathological finding of aorta tissues with Hematoxylin and Eosin (H\&E) stain confirmed the biochemical results in all tested groups. The microscopic examination of aorta tissues of rats from the healthy control group showed normal histological structure of the tunica intima lined by flattened endothelial cells in the straight surface using (H\&E 400) as shown in Figure 5 photomicrograph (a). On the other hand, HFHF- fed rat's aorta tissues showed swelling and corrugation of the endothelial cells that lining the intima that leading to thrombosis. These early changes can possibly lead to endothelial dysfunction as shown in photomicrograph (b).
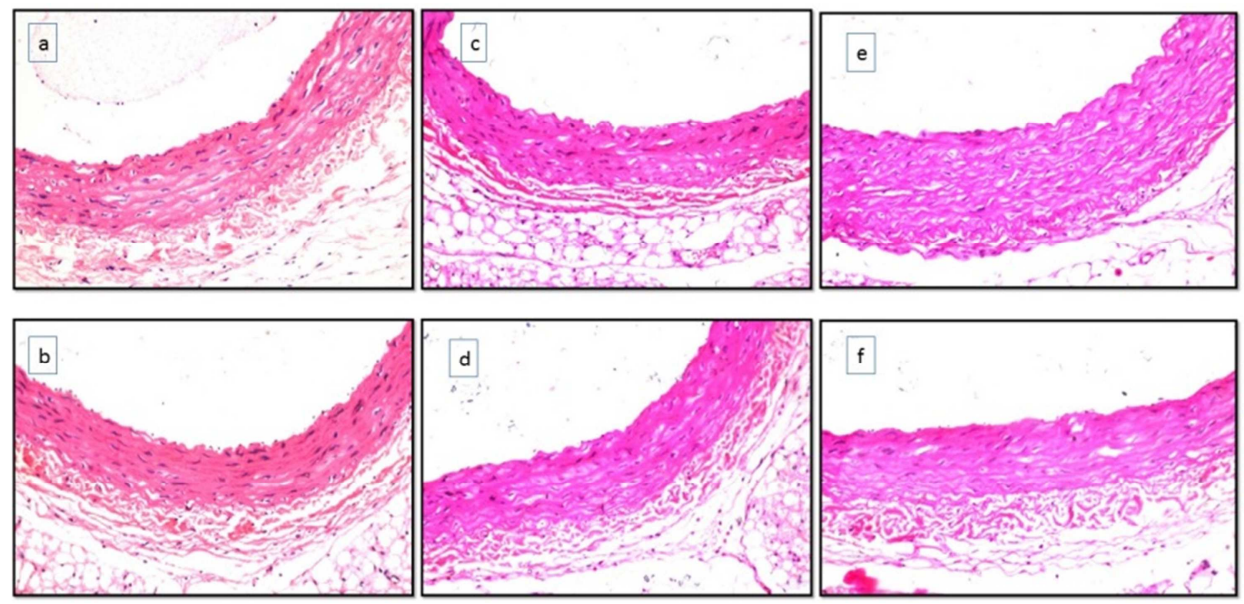

Figure 5. Photomicrograph (a) aorta tissue of rats fed balanced diet showing there was no histopathological alteration and the normal intact histological structure of the tunica intima which was lined by flattened endothelium in the straight surface as well as the underlying media then adventitia (H\&E $x 400)$. Photomicrograph (b) of aorta tissue of rats fed HFHF showing swelling (stars) in the lining endothelium of the intima with corrugation (arrows) in the surface were observed which assisting the process of thrombosis in the vascular lumen (H\&E x400). Photomicrograph (c) of aorta tissue of rats fed HFHF $+5 \%$ olive seed group showing swelling inlining of the endothelium of the intima (stars) with vacuolization (arrows) in the tunica media (H\&E $x 400$ ). Photomicrograph (d) of aorta tissue of rats HFHF $+10 \%$ olive seed group showing straight-lining of the endothelium of the intima with vacuolization (arrows) in the tunica media (H\&E x400). Photomicrograph (e) of aorta tissue of rats fed HFHF $+5 \%$ nano olive seed group showed normal histological structure of the straightlining of the endothelium of the intima as well as the histological structure of the media (H\&E x400). Photomicrograph (f) of aorta tissue of rats fed HFHF $+10 \%$ nano olive seed group showing normal histological structure of endothelium of the intima as well as the histological structure of the media (H\&E x400). 
Olive seeds powder dietary supplementation in the native form at $5 \%$ and $10 \%$ levels showed slight improvement as shown in figure 5 photomicrograph (c and d). Meanwhile, dietary supplementation with olive seed in nano form at $5 \%$ and $10 \%$ ameliorated the pathological changes induced in HFHF fed rats indicated by reversing the swelling and corrugation that resulted from HFHF diet, this illustrated in Figure 5 photomicrograph (e and $\mathrm{f}$ ). The results of the present study confirmed by the previous results of Yoo et al. [13] who showed that the abdominal aorta of rats fed on HFHF diet was thicker in comparison to the aorta of rats group fed on a regular diet.

Moreover, the current study was agreed with Poudyal et al. [68] who demonstrated that olive polyphenols supplementation protected the aorta against the free radical-induced impairment of the NO-mediated relaxation, thereby preserving the role of vascular endothelium in the vasodilation process.

Also, results of Suzuki et al. [88] reported that ferulic acid may relax the aorta even after the removal of the intact endothelium, which confirms a direct effect of ferulic acid on vascular smooth muscle cells.

\section{Conclusion}

Olive seed powder either in native or nano form showed a significant ameliorative effect against deleterious metabolic dysregulation induced by high fat high fructose diet. The present study suggests also that treatment with nano or native olive seeds powder improves endothelial function by improving NO bioavailability, increasing eNOS activity, reducing insulin resistance, improving lipid profiles, and preventing the generation of both vasoconstrictors, and vascular adhesion molecules. The improvement in the altered parameters was more pronounced in nano olive seed supplemented groups than other remaining groups supplemented with olive seed in native form. These results confirmed that nano-capsulation increases the bioavailability of polyphenols in olive seed powder.

The results of this study suggests the use of olive seed powder as functional food due to its powerful antioxidant and anti-inflammatory activities to alleviate and protect against insulin resistance and its subsequent complications as type 2 diabetes and endothelial dysfunction.

\section{Ethics Approval and Consent to Participate}

This study follows guidelines for the care and use of experimental animals established by the Committee for control and supervision of experiments on animals. Animal procedures were also made in accordance with the Faculty of Science protocol, Ain Shams University.

\section{Competing Interests}

The authors declare that they have no competing interests.

\section{Acknowledgements}

The authors are greatly thankful to Prof. Dr. Adel M. Bakeer, professor of pathology, Faculty of Veterinary Medicine, Cairo University for helping and valuable comment in histopathological studies. The authors are greatly thankful to Prof. Dr. Laila Rashed, professor of Medical Biochemistry and Molecular biology, Faculty of Medicine, Cairo University for performing ELIZA analyses in the Biochemistry and Molecular biology Unit.

\section{References}

[1] Park, K. H., Park, W. J., 2015. Endothelial dysfunction: clinical implications in cardiovascular disease and therapeutic approaches. The Korean Academy of medical science, 30: 1213-1225.

[2] Sun, H. J., Wu, Z. Y., Nie, X. W., Bian, J. S., 2020. Role of Endothelial Dysfunction in Cardiovascular Diseases: The Link Between Inflammation and Hydrogen Sulfide. Frontiers in Pharmacology, 10 (1568): 1-15.

[3] Lu, T. M., Chung, M. Y., Lin, M. W., Hsu, C. P, Lin, S. J., 2011. Plasma asymmetric dimethylarginine predicts death and major adverse cardiovascular events in individuals referred for coronary angiography. Int J Cardiol. 153 (2): 135-140.

[4] Tappy, L., Le, K. A., 2010. Metabolic effects of fructose and the worldwide increase in obesity. Physiological Reviews, 90: 23-46.

[5] Nelson, R. H., 2013. Hyperlipidemia as a risk factor for cardiovascular disease. Primary Care Journal, 40: 195-211.

[6] Lorber, D., 2014. Importance of cardiovascular disease risk management in patients with type 2 diabetes mellitus. Diabetes Metabolic Syndrome and Obesity, 7: 169-183.

[7] Lasker, S., Rahman, M. M., Parvez, F., Zamila, M., Miah, P., Nahar, K., Kabir, F., Sharmin, S. B., Subhan, N., Ahsan, G. U., Alam, M. A., 2019. High-fat diet-induced metabolic syndrome and oxidative stress in obese rats are ameliorated by yogurt supplementation. Science Review, 9 (1): 20026.

[8] Elrashidy, R. A., Zhang, J., Liu, G., 2019. Long-term consumption of Western diet contributes to endothelial dysfunction and aortic remodeling in rats: Implication of Rhokinase signaling. Clinical and Experimental Hypertension, 41 (2): 174-180.

[9] Abdelbaky, M. S. M. E., Ibrahim, H. S., Hassan, M. L., Sayed, Z. E., 2016. The Impact of Olive Seeds (Olea europaea L.) Powder (OSP) and its Nanoparticles (NOS) on Obese Hyperlipidemic Rats. ARC Journal of Nutrition and Growth, 2 (1): $28-40$.

[10] Huang, Q, R., Given, P., Qian, M., 2009. Micro/nanoencapsulation of active food ingredients. American Chemical Society Symposium Series. 1007th vol. Washington (DC): Oxford University Press. 2009.

[11] Ross, S. A., Srinivas, P. R., Clifford, A. J., Lee, S. C., Philbert, M. A., Hettich, R. L., 2004. New technologies for nutrition research. J Nutr. 134 (3): 681-685. 
[12] Reeves, P. G., Nielsen, F. H. Fahey, G. C., 1993. AIN-93 Purified Diets for Laboratory Rodents: Final Report of the American Institute of Nutrition Ad Hoc Writing Committee on the Reformulation of the AIN-76A Rodent Diet. American Journal of Nutrition; 123 (11): 1939-1951.

[13] Yoo, S. Y., Ahn, H., Park, Y. K., 2016. High dietary fructose intake on cardiovascular disease related parameters in growing rats. Journal of Nutrients, 9 (1): 1-12.

[14] AOAC. (2000): Official method of analysis934.01 (17th Edition) Volum 1. Association of Official Analytical Chemists Inc. Maryland, USA.

[15] Trinder, P., 1969. Determination of blood glucose using an oxidase-peroxidase system with a non-carcinogenic chromogen. Journal of Clinical Pathology, 22 (2): 158-161.

[16] Sapin R, Ongagna J. C., Gasser, F., Grucker D., 1998. Insulin measurements in haemolysed serum: influence of insulinase inhibitors. Clinical Chemistry Acta, 274 (2): 111-117.

[17] Matthews, D. R., Hosker, J. P., Rudenski, A. S., Naylor B. A., Treacher, D. F., Turner, R. C., 1985. Homeostasis model assessment: Insulin resistance and beta-cell function from fasting plasma glucose and insulin concentrations in man. Diabetologia, 28 (7): 412-419.

[18] Lombard, S., Helmy, M. E., Pieroni, G., 2001. Lipolytic activity of ricin from Ricinus sanguineus and Ricinus communis on neutral lipids. Biochemistry Journal, 358 (3): 773-781.

[19] Allain, C. C., Poon, L. S., Chan, C. S. G., Richmond, W., Fu, P. C., 1974. Enzymatic determination of total serum cholesterol. Clinical Chemistry, 20 (4): 470-475.

[20] Fassati, P., Prencipe, L., 1982. Serum triglycerides determined colorimetrically with an enzyme that produces hydrogen peroxide. Journal of Clinical Chemistry, 28 (10): 2077-2080.

[21] Lopez-Virella, M. F. L., Stone, P. G., Colwell, J. A., 1977. Enzymatic determination of serum High density lipoprotein. Diabetologia, 13: 285-291.

[22] Friedewald, W. T., Levy, R. I., Fredrickson, D. S., 1972. Estimation of the concentration of low-density lipoprotein cholesterol in plasma, without use of the preparative ultracentrifuge. Journal of clinical chemistry, 18 (6): 499-502.

[23] Roberts, W. L., Sedrick, R., Moulton, L., Spencer, A., Rifai, N., 2000. Evaluation of Four Automated High-Sensitivity CReactive Protein Methods: Implications for Clinical and Epidemiological Applications. Clinical Chemistry Journal, 46 (4): 461-468.

[24] Peters, M., Müller, A. M., Rose-John, S., (1998). Interleukin-6 and soluble interleukin- 6 receptor: direct stimulation of gp130 and hematopoiesis. Blood, 92 (10): 3495-3504.

[25] Docherty, J. C., Gerrard, J. M., 1986. An enzyme-linked immunosorbent assay for 6-keto-PGFIa. Prostaglandins, 31 (3): $375-383$.

[26] Wakisaka, S., Kubota, T., Ando, K., Aihara, M., Inoue, H., Ishida, H., 1996. Endothelin -1 kinetics in plasma, urine, and blister fluid in burn patients. Annal of plastic surgery. 37 (3) 305-3.

[27] Besemer, J., Harant, H., Wang, S., Oberhauser, B., Marquardt, K., Foster, C. A., Schreiner, E. P., Vries, J. E., Dascher-Nadel,
C., Lindely, I. J. D., 2005. Selective inhibition of cotranslational translocation of vascular cell adhesion molecule 1. Nature. 436 (7048): 290-293.

[28] Zheng, F., Chevalier, J. A., Zhang, L. Q., Virgil, D., Ye, S. Q., Kwiterovich, P. O., 2001. An Hphl polymorphism in the Eselectin gene is associated with premature coronary artery disease. Clinical Genetics Journal, 59 (1): 58-64.

[29] Ohkawa, H., Ohishi, N., Yagi, K., 1979. Assay of lipid peroxidase in animal tissues by thiobarbituric acid reaction. Journal of Analytical Biochemistry, 95 (2): 351-358.

[30] Montgomery, H. A. C., Dymock, J., 1961. Nitric oxide determination. Analyst Journal, 86: 414-416.

[31] Ju, H., Zou, R., Venema, V. I., Venema, R. C., 1997. Direct Interaction of Endothelial Nitric-oxide Synthase and Caveolin-1 Inhibits Synthase Activity. Journal of Biological Chemistry, 272 (30): 18522-18225.

[32] Banchroft, J. D., Stevens, A., Turner, D. R., 1996. Theory And Practice OF Histological Techniques. Fourth Ed. Churchill Livingstone, New York, London, San Francisco, Tokyo.

[33] Levesque, R., 2007. SPSS Programming and Data Management: A Guide for SPSS and SAS users. 3th Edition, United States of America.

[34] Rodriguez, G., Lama, A., Rocio Rodriguez, Jimeinez, A., Guillein, R., Ferna'ndez-Bolaños, J., 2008. Olive stone an attractive source of bioactive and valuable compounds. Bioresource Technology, 99 (13): 5261-5269.

[35] Bianchi, G., 2003. Lipids and phenols in table olives. European Journal of Lipid Science and Technology, 105 (5): 229-242.

[36] Naghmouchi, I., Mutjé, P., Boufi, S., 2015. Olive stones flour as reinforcement in polypropylene composites: A step forward in the valorization of the solid waste from the olive oil industry. Industrial Crops and Products, 72 (5): 183-191.

[37] Basciano, H., Federico, L., Adeli, K., 2005. Fructose, insulin resistance, and metabolic dyslipidemia. Nutrition and Metabolism, 2 (1): 2-5.

[38] Tran, L. T., Yuen, V. G., McNeill, J. H., 2009. The fructosefed rat: A review on the mechanisms of fructose-induced insulin resistance and hypertension. Molecular and Cellular Biochemistry; 332 (1-2) 145-159.

[39] Rao, A., Pandya, V., Whaley-Connell, A., 2015. Obesity and insulin resistance in resistant hypertension: implications for the kidney. Advances in Chronic Kidney Disease, 22 (3): 211-217.

[40] Prieto, D., Contreras, C., Sa'nchez, A., 2014. Endothelial dysfunction, obesity, and insulin resistance. Current Vascular Pharmacology, 12 (3): 412-426.

[41] Lozano, I., Van der Werf, R., Bietiger, W. William Bietiger1, Seyfritz, S., Peronet, C., Pinget, M., Jeandidier, N., Maillard, E., Marchioni, E., Sigrist, S and Dal, S., 2016. High-fructose and high-fat diet-induced disorders in rats: impact on diabetes risk, hepatic, and vascular complications. Nutrition \& Metabolism, 13 (15): 1-13.

[42] Jemai, H., El Feki, A., Sayadi, S., 2009. Antidiabetic and antioxidant effects of hydroxytyrosol and oleuropein from olive leaves in alloxan-diabetic rats. Journal of Agriculture and Food Chemistry, 57 (19): 8798-8804. 
[43] Wang, N., Liu, Y., Ma, Y., and Wen, D., 2018. Hydroxytyrosol ameliorates insulin resistance by modulating endoplasmic reticulum stress and prevents hepatic steatosis in diet-induced obesity mice. The Journal of Nutritional Biochemistry, 57: 180-188.

[44] Pirozzi, C., Lama, A., Simeoli, R., Paciello, O., Pagano, T. B., Mollica, M. P., Di Guida, F., Russo, R., Magliocca, S., Canani, R. B., Raso, G. M., Calignano, A., Meli, R., 2016. Hydroxytyrosol prevents metabolic impairment reducing hepatic inflammation and restoring duodenal integrity in a rat model of NAFLD. Journal of Nutritional Biochemistry, 30: $108-115$.

[45] Ortiz-Andrade, R. R., Sánchez-Salgado, J. C., NavarreteVázquez, G., Webster, S. P., Binnie, M., Garcia-Jimenez, S., Leon-Rivera, I., Cigarroa-Vazquez, P., Villalobos-Molina, R., Estrada-Soto, S., 2008. Antidiabetic and toxicological evaluations of naringenin in normoglycaemic and NIDDM rat models and its implications on extra-pancreatic glucose regulation. Diabetes, Metabolic Syndrome and Obesity, 10 (11): 1097-1104.

[46] Pu, P., Gao, D., Mohamed, S., Chen, J., Zhang, J., Zhou, X. Y., Jiang, H., 2012. Naringenin ameliorates metabolic syndrome by activating AMP activated protein kinase in mice fed a high-fat diet. Archives of Biochemistry and Biophysics, 518 (1): 61-70.

[47] Manach, C., Scalbert, A., Morand, C., Rémésy C, Jiménez, L., 2004. Polyphenols: food sources and bioavailability. American Journal of Clinical Nutrition, 79 (5): 727-747.

[48] Maity, S., Mukhopadhyay, P., Kundu, P. P., Chakraborti, A. S., 2017. Alginate coated chitosan core-shell nanoparticles for efficient oral delivery of naringenin in diabetic animals - an in vitro and in vivo approach. Carbohydrate Polymers, 15 (170): $124-132$.

[49] Wang, S., Du, L. B., Jin, L., Wang, Z., Peng, J., Liao, N., Zhao, Y., Zhang, J., Pauluhn, c, J., Hai, C., Wang, X., Li, W., 2018. Nano oleanolic acid alleviates metabolic dysfunctions in rats with high fat and fructose diet. Biomedicine \& Pharmacotherapy Journal, 108: 1181-1187.

[50] Becerra-Tomas, N., Diaz-Lopez, A., Rosique-Esteban, N., Ros, E., Buil-Cosiales, P., Corella, D., Estruch, R., Fito, M., SerraMajem, L., Aros, F., Lamuela-Raventos, R. M., Fiol, M., Santos-Lozano, J. M., Diez-Espino, J., Portoles, O., SalasSalvado, J., 2017. Legume consumption is inversely associated with type 2 diabetes incidence in adults: a prospective assessment from the PREDIMED study. Clinical Nutrition Journal, 37 (3): 906-913.

[51] Tveden-Nyborg, P., Birck, M. M., Ipsen, D. H., Thiessen, T., de Bie Feldmann, L., Lindblad, M. M., Jensen, H. E., Lykkesfeldt, J., 2016. Diet-induced dyslipidemia leads to nonalcoholic fatty liver disease and oxidative stress in Guinea pigs. Journal of Translation Research, 168: 146-160.

[52] Zhuhua, Z., Zhiquan, W., Zhen, Y., Yixin, N., Weiwei, Z., Xuaoyong, L., Yueming, L., Hongmei, Z., Li, Q., Qing, S., 2015. A novel mice model of metabolic syndrome: the highfat_high-fructose diet-fed ICR mice. Experimental Animal Journal, 64 (4): 435-442.

[53] Li, T., Lu, X., Sun, Y., Yang, X., 2016. Effects of spinach nitrate on insulin resistance, endothelial dysfunction markers, and inflammation in mice with high-fat and highfructose consumption. Food \& Nutrition Research, 60:
320-330.

[54] Angelopoulos, T. J., Lowndes, J., Zukley, L. Melanson, K. J., Nguyen, V., Huffman, A., Rippe, J. M., 2009. The effect of high-fructose corn syrup consumption on triglycerides and uric acid. Journal of Nutrition, 139 (6): 1242S-1245S.

[55] Prados, I., Orellana, J. M., Marina, M. L., García, M. C., 2020. Identification of peptides potentially responsible for in vivo Hypolipidemic activity of a hydrolysate from olive seeds. Journal of Agriculture and Food Chemistry, 68 (14): 4237 4244.

[56] Ruiz-Roso, B., Quintela, J. C., de la Fuente, E., Haya, J., Pérez-Olleros, L., 2010. Insoluble Carob Fiber Rich in Polyphenols Lowers Total and LDL Cholesterol in Hypercholesterolemic Subjects. Plant Foods for Human Nutrition, 65 (1): 50-56.

[57] Yu, G. U. I., Hong-jia, L. U., Duan-li, Z. H. A. N. G., 2014. Hypolipidemic Effects of Different Particle Sizes of Cellulose from Sweet Potato Residue in Ovariectomized Hyperlipidemia Rats. Journal of Food Science, 35 (5): 218-222.

[58] Abdelbaky, M. S. M. E., Ibrahim, H. S., Hassan, M. L., Sayed, Z. E., 2016. Nanoparticles Effects of Red Grape (Vitis vinifera) Seeds and Grape Seeds Powder on Obese Hyperlipidemic Rats. ARC Journal of Nutrition and Growth (AJNG), (2) 2: 115 .

[59] Paiva-Martins, F., Kiritsakis, A., 2017. Olive fruit and olive oil composition and their functional compounds. In: Shahidi F, Kiritsakis A, editor. Olives and Olive Oil as Functional Foods: Bioactivity, Chemistry, and Processing. p. 81-115.

[60] Andreasen, M. F., Landbo, A. K., Christensen, L. P., Hansen, A., Meyer, A. S., 2001. Antioxidant effects of phenolic rye (Secale cereale L.) extracts, monomeric hydroxycinnamates, and ferulic acid dehydrodimers on human low-density lipoproteins. Journal of Agriculture and Food Chemistry, 49 (8): 4090-4096.

[61] Assini, J. M., Mulvihill, E. E., Sutherland, B. G., Telford, D. E., Sawyez, C. G., Felder, S. L., Chhoker, S., Edwards, J. Y., Gros, R., Huff, M. W., 2013. Naringenin prevents cholesterolinduced systemic inflammation, metabolic dysregulation, and atherosclerosis in Ldlr-/-mice. Journal of Lipid Research, 54 (3): 711-724.

[62] Bunbupha, S., Prachaney, P., Apaijit, K., Kukongviriyapan, U., Pakdeechote, P., 2019. Gallic acid ameliorates hypertension, insulin resistance, and dyslipidemia in high-fructose dietinduced metabolic syndrome rats. Isan Journal of Pharmaceutical Sciences, 15 (1): 158-165.

[63] Delbosc, S., Paizanis, E., Magous, R., Araiz, C., Dimo, T., Cristol, J., Cros, G., Azay, J., 2005. Involvement of oxidative stress and NADPH oxidase activation in the development of cardiovascular complications in a model of insulin resistance, the fructose-fed rat. Atherosclerosis, 179 (1): 43-49.

[64] Busserolles, J., Zimowska, W., Rock, E., Rayssiguier, Y., Mazur, A., 2002. Rats fed a high sucrose diet have altered heart antioxidant enzyme activity and gene expression. Life Science Journal, 71 (11): 1303-1312.

[65] Cosenzi, A., Bernobich, E., Bonavita, M., Gris, F., Odoni, G., and Bellini, G., 2002. Role of nitric oxide in the early renal changes induced by high fructose diet in rats. Kidney Blood Pressure Research, 25: 363-369. 
[66] Zhang, D. M., Jiao, R. Q., and Kong, L. D., 2017. High Dietary Fructose: Direct or Indirect Dangerous Factors Disturbing Tissue and Organ Functions. Nutrients, 9 (4): 335.

[67] Qian L. B., Wang H. P., Chen Y., Chen F. X., Ma Y. Y., Bruce, L. C., Xia, Q. 2010. Luteolin reduces high glucose-mediated impairment of endothelium dependent relaxation in rat aorta by reducing oxidative stress. Pharmacology Research, 61 (4): 281-287.

[68] Poudyal, H., Campbell, F., Brown, L., 2010. Olive leaf extract attenuates cardiac, hepatic, and metabolic changes in high carbohydrate-, high fat-fed rats. Journal of Nutrition, 140 (5): 946-953.

[69] Bulotta, S., Celano, M., Lepore, S. M., Montalcini, T., Pujia, A., Russo, D., 2014. Beneficial effects of the olive oil phenolic components oleuropein and hydroxytyrosol: focus on protection against cardiovascular and metabolic diseases. Journal of Translational Medicine, 3 (12): 219-228.

[70] Liu, Z., Jiang, C., Zhang, J., Liu, B., Du, Q., 2016. Resveratrol inhibits inflammation and ameliorates insulin resistant endothelial dysfunction via regulation of AMPK and SIRT1 activities1. Journal of Diabetes, 8 (3): 324-35.

[71] Cavia-Saiz, M., Busto, M. D., Pilar Izquierdo, M. C., Ortega, N., Perez_Mateos, M., Muniz, P., 2010. Antioxidant properties, radical scavenging activity, and biomolecule protection capacity of flavonoid naringenin and its glycoside Naringenin: A comparative study. The Journal of the Science of Food and Agriculture, 90 (7): 1238-1244.

[72] Miler, M., Živanović, J., Ajdžanović, V., Oreščanin-Dušić, Z., Milenković, D., 2016. Citrus flavanones naringenin and hesperetin improve antioxidant status and membrane lipid compositions in the liver of old-aged Wistar rats. Experimental Gerontology, 84 (61): 49-60.

[73] Zygmunt, K., Faubert, B., MacNeil, J., Tsiani, E., 2010. Naringenin, a citrus flavonoid, increases muscle cell glucose uptake via AMPK. Biochemical and Biophysical Research Communications, 398 (2): 178-183.

[74] Esmaeili, M. A., Alilou, M., 2014. Naringenin attenuates $\mathrm{CCl} 4$ induced hepatic inflammation by the activation of $\mathrm{Nrf2}$ mediated pathway in rats. Clinical and Experimental Pharmacology and Physiology, 41 (6): 416-422.

[75] Grooms, K. N., Ommerborn, M. J., Pham, D. Q., Djousse, L., Clark, C. R., 2013. Dietary fiber intake and cardiometabolic risks among US adults, NHANES 1990-2010. The American Journal of Medicine, 126 (12): 1059-1067.

[76] Bourgoin, F., Bachelard, H., Badeau, M., Melancon, S., Pitre, M., Lariviere, R., Nadeau, A., 2008. Endothelial and vascular dysfunction and insulin resistance in rats fed a high-fat, highsucrose diet. American Journal of Physiology and Heart Circulatory Physiology, 295 (3): H1044-H1055.

[77] Karbach, S., Wenzel, P., Waisman, A., Munzel, T., Daiber, A., 2014. eNOS uncoupling in cardiovascular diseases--the role of oxidative stress and inflammation. Current Pharmaceutical Design, 20 (22): 3579-3594.

[78] Łuczak, A., Madej, M., Kasprzyk, A., Doroszko, A., 2020. Role of the eNOS Uncoupling and the Nitric Oxide Metabolic Pathway in the Pathogenesis of Autoimmune Rheumatic Diseases. Oxidative Medicine and Cellular Longevity, 13: 1-15.

[79] Yeager, M. E., Belchenko, D. D., Nguyen, C. M., Colvin, K. L., Ivy, D. D., Stenmark, K. R., 2012. Endothelin-1, the unfolded protein response, and persistent inflammation: role of pulmonary artery smooth muscle cells. American Journal of Respiratory Cell and Molecular Biology, 46 (1): 14-22.

[80] Omar, S. H., 2010. Cardioprotective and neuroprotective roles of oleuropein in olive. Saudi Pharmaceutical Journal, 18 (3): 111-121.

[81] Summerhill, V., Karagodin, V., Grechko, A., Myasoedova, V., Orekhov, A., 2018. Vasculoprotective role of olive oil compounds via modulation of oxidative stress in atherosclerosis. Journal of Frontiers in Cardiovascular Medicine, 21 (5): 188.

[82] Fotis L., Agrogiannis G., Vlachos I. S., Pantopoulou A., Margoni A., Kostaki, M., Verikokos, C., Tzivras, D., Mikhailidis, D. P., Perrea, D., 2012. Intercellular adhesion molecule (ICAM)-1 and vascular cell adhesion molecule (VCAM)-1 at the early stages of atherosclerosis in a rat model, in vivo. Hormones, 26 (2): 243-250.

[83] Cook-Mills, J. M., Marchese, M. E., Abdala-Valencia, H., 2011. Vascular cell adhesion molecule-1 expression and signaling during disease: regulation by reactive oxygen species and antioxidants. Antioxidants and Redox Signaling, 15 (6): $1607-1638$.

[84] Kowalczyk, A., Kleniewska, P., Kolodziejczyk, M., Skibska, B., Goraca, A., 2015. The role of endothelin-1 and endothelin receptor antagonists in inflammatory response and sepsis. Archivum Immunologiae et Therapiae Experimentalis, 63 (1): 41-52.

[85] Leibowitz, A., Rehman, A., Paradis, P., Schiffrin, E. L., 2013. Role of the regulatory lymphocytes in the pathogenesis of high-fructose diet-induced metabolic syndrome. Hypertension, 61 (6): 1316-1321.

[86] Kho, M. C., Lee, Y. J., Cha, J. D., Choi, K., Kang, D. G., Lee, H. S., 2014. Gastrodia elata ameliorates high-fructose diet-induced lipid metabolism and endothelial dysfunction. Evidence-Based Complementary and Alternative Medicine, 45 (4): 1-10.

[87] Crespo, M. C., Tomé-Carneiro, J., Dávalos, A., Visioli, F., 2018. Pharma-nutritional properties of olive oil phenols. Transfer of new findings to human nutrition. Foods Journal, 7 (6): 90 .

[88] Suzuki, A., Yamamoto, M., Jokura, H., Fujii, A., Tokimitsu, I., Hase, T., Saito, I., 2007. Ferulic acid restores endotheliumdependent vasodilation in aortas of spontaneously hypertensive rats. American Journal of Hypertension, 20 (5): 508-513. 